\title{
Clinical, genetic, and pathologic characterization of FKRP Mexican founder mutation c.1387A >G
}

Angela J. Lee, BA,* Karra A. Jones, MD, PhD,* Russell J. Butterfield, MD, PhD, Mary O. Cox, BS, Chamindra G. Konersman, MD, Carla Grosmann, MD, Jose E. Abdenur, MD, Monica Boyer, NP, Brent Beson, MD, Ching Wang, MD, James J. Dowling, MD, PhD, Melissa A. Gibbons, MS, Alison Ballard, NP, Joanne S. Janas, MD, Robert T. Leshner, MD, Sandra Donkervoort, MS, CGC, Carsten G. Bönnemann, MD, Denise M. Malicki, MD, PhD, Robert B. Weiss, PhD, Steven A. Moore, MD, PhD, and Katherine D. Mathews, MD

Neurol Genet 2019;5:e315. doi:10.1212/NXG.0000000000000315

\section{Abstract}

\section{Objective}

To characterize the clinical phenotype, genetic origin, and muscle pathology of patients with the FKRP c.1387A>G mutation.

\section{Methods}

Standardized clinical data were collected for all patients known to the authors with c.1387A $>\mathrm{G}$ mutations in FKRP. Muscle biopsies were reviewed and used for histopathology, immunostaining, Western blotting, and DNA extraction. Genetic analysis was performed on extracted DNA.

\section{Results}

We report the clinical phenotypes of 6 patients homozygous for the c.1387A>G mutation in FKRP. Onset of symptoms was $<2$ years, and 5 of the 6 patients never learned to walk. Brain MRIs were normal. Cognition was normal to mildly impaired. Microarray analysis of 5 homozygous FKRP c.1387A $>$ G patients revealed a 500-kb region of shared homozygosity at 19q13.32, including FKRP. All 4 muscle biopsies available for review showed end-stage dystrophic pathology, near absence of glycosylated $\alpha$-dystroglycan ( $\alpha$-DG) by immunofluorescence, and reduced molecular weight of $\alpha$-DG compared with controls and patients with homozygous FKRP c.826C >A limb-girdle muscular dystrophy.

\section{Conclusions}

The clinical features and muscle pathology in these newly reported patients homozygous for FKRP c.1387A $>\mathrm{G}$ confirm that this mutation causes congenital muscular dystrophy. The clinical severity might be explained by the greater reduction in $\alpha$-DG glycosylation compared with that seen with the c.826C $>$ A mutation. The shared region of homozygosity at $19 \mathrm{q} 13.32$ indicates that FKRP c. $1387 \mathrm{~A}>\mathrm{G}$ is a founder mutation with an estimated age of 60 generations ( 1,200-1,500 years).

\author{
Correspondence \\ Dr. Jones \\ karra-jones@uiowa.edu
}




\section{Glossary}

CMD = congenital muscular dystrophy; DSHB = Developmental Studies Hybridoma Bank; EF = ejection fraction; H\&E = hematoxylin and eosin; HRC = Haplotype Reference Consortium; IF = immunofluorescence; IRB = institutional review board; LGMD2I = limb-girdle muscular dystrophy type 2I; SNP = single nucleotide polymorphism; WGA = wheat germ agglutinin; $\boldsymbol{\alpha}$-DG $=\alpha$-dystroglycan; $\beta$-DG $=\beta$-dystroglycan.

Dystroglycanopathies are muscular dystrophies resulting from hypoglycosylation of $\alpha$-dystroglycan ( $\alpha$-DG), a protein in the dystrophin-glycoprotein complex. ${ }^{1-3}$ More than 17 genes are required for proper $\alpha$-DG functional glycosylation; FKRP is one of the most commonly mutated genes. ${ }^{4}$ It was recently shown that FKRP functions as a ribitol 5-phosphate transferase. $^{5}$

FKRP mutations result in highly variable phenotypes, ranging from severe congenital muscular dystrophy (CMD) to mild limb-girdle muscular dystrophy type 2 I (LGMD2I). ${ }^{6,7}$ The most common founder mutation (c.826C $>$ A, p.Leu276Ile) is associated with an LGMD2I phenotype. ${ }^{8,9}$ Muscle biopsies from patients with LGMD2I show mild to moderate dystrophic changes and highly variable partial reduction in immunostaining for glycosylated $\alpha$-DG. ${ }^{10}$

In 2007, a novel homozygous FKRP mutation (c.1387A>G, p.Asn463Asp) was identified in 2 Mexican American girls; the authors suggested a possible founder mutation. ${ }^{11}$ The 2 patients had hypotonia at birth and never achieved the ability to stand or walk. Both girls had a marked reduction in glycosylated $\alpha$-DG and decreased laminin $\alpha 2$ (merosin) immunostaining. ${ }^{11}$ A third Mexican patient homozygous for FKRP c. $1387 \mathrm{~A}>\mathrm{G}$ had a slightly milder clinical course with independent ambulation between 14 and 24 months of age ${ }^{12}$; no muscle biopsy immunostaining was reported.

We have identified 6 additional patients homozygous for the FKRP c.1387A $>\mathrm{G}$ variant and 3 compound heterozygous patients with the FRKP c.1387A $>\mathrm{G}$ and the FKRP c.826C $>\mathrm{A}$ mutations. Here, we describe the clinical and pathologic features of these cases and provide genetic evidence that c. $1387 \mathrm{~A}>\mathrm{G}$ is a founder mutation originating in preColumbian central Mexico.

\section{Methods}

\section{Patient data collection}

Standardized clinical data were collected for all patients known to the authors with a c.1387A $>\mathrm{G}$ mutation in FKRP. Patients were identified through diagnostic testing in the Department of Pathology at The University of Iowa, personal communications, or through patient participation in the Iowa Wellstone Center dystroglycanopathy natural history study (clinical trials identifier NCT00313677). The clinical teams involved in the patients' care abstracted the clinical data, including results from genetic testing, from the medical records using a standardized data collection form, and the deidentified information was collated centrally.

\section{Genotype and haplotype analysis}

The FKRP mutations were identified or confirmed through clinical testing in Clinical Laboratory Improvement Amendments-certified laboratories. Identification of the FKRP mutation for patient 4 was initially done through whole-exome sequencing using Broad dual-barcoded library construction followed by the Illumina Rapid Capture Exome enrichment kit with $38 \mathrm{Mb}$ target territory (29 Mb baited).

Genome-wide single nucleotide polymorphism (SNP) genotyping was performed on genomic DNA using Illumina Human Infinium Omni2.5Exome-8 v1.3 BeadChips. Samples were processed on an Illumina iScan system using standard Illumina protocols, and genotypes were called with Illumina GenomeStudio software. Genotypes were cleaned using PLINK 1.9 software, ${ }^{13}$ yielding an average genotyping rate of $99.8 \%$ and between 2,594,691 to 2,602,822 genotypes per sample. Phased haplotypes for chromosome 19 were computed from unphased genotypes using the Eagle2 software and the Haplotype Reference Consortium (HRC r.1.1) reference panel of human haplotypes, executed on the Michigan Imputation Server. ${ }^{14}$ The age of the founder mutation was estimated using the Gamma method assuming a correlated "tree-like" genealogy applied to the genetic length of the ancestral segment lengths surrounding the FKRP mutation. ${ }^{15}$ Ancestry inference combined patient genotypes with 1000 Genomes Project Illumina Omni2.5 genotypes merged from ALL.chip.omni_broad_sanger_combined.20140818.snps.genotypes.vcf.gz (ftp.1000genomes.ebi.ac.uk/voll/ftp/release/ 20130502/supporting/hd_genotype_chip). The merged genotype set was pruned for linked SNPs using PLINK indeppairwise functionality with the arguments 100050 0.2, keeping 135,080 unlinked SNPs for subsequent ancestry analysis using the program ADMIXTURE with $K=3$ ancestral populations. ${ }^{16}$

\section{Muscle biopsy evaluation}

All available muscle biopsies from these patients were reviewed and re-evaluated (K.A.J. and S.A.M.). Frozen sections of skeletal muscle were evaluated at The University of Iowa using standard hematoxylin and eosin ( $\mathrm{H} \& \mathrm{E})$ staining and immunofluorescence (IF). Immunostaining was performed using the following antibodies: dystrophin, carboxy terminus (rabbit polyclonal ab15277; Abcam, Cambridge, UK); $\alpha$-DG (clone IIH6; Developmental Studies Hybridoma Bank (DSHB), The University of Iowa), $\beta$-DG (clone 7D11; DSHB), and merosin (laminin a2) (clone 5H2; Millipore 
Sigma, Massachusetts, US). Secondary antibodies used included goat anti-rabbit immunoglobulin $\mathrm{G}(\mathrm{IgG})$, goat antimouse IgM, or goat anti-mouse IgG all labeled with AlexaFluor488 (Life Technologies, Carlsbad, CA). Immunostains were analyzed in a blinded manner by standard fluorescence microscopy. The intensity of staining with each antibody was graded from zero (absent) to 3+ (normal expression). Control human skeletal muscle was included with research patient material on each glass slide immunostained in the study.

\section{Western blotting}

Pooled cryosections cut from selected muscle biopsies were used for Western blotting at The University of Iowa. Wheat germ agglutinin (WGA) glycoprotein preparations were performed and samples run on $3 \%-15 \%$ gradient gels as previously described. ${ }^{17,18}$ Antibodies used for blotting included IIH6 (gift from Kevin P. Campbell, The University of Iowa) and AF6868 (R\&D Systems, Minneapolis, MN). Blots were imaged on an Odyssey infrared fluorescence imaging system (Li-Cor Biosciences, Lincoln, NE).

\section{Standard protocol approvals and patient consents}

The University of Iowa institutional review board approved this study (IRB\# 201703860). Initial sequencing for patient 4 was approved by the NIH/NINDS Institutional Review Board (IRB\# 12-N-0095). Informed consent was obtained from all participants who had muscle biopsy tissue stored in the Iowa Wellstone Center Tissue Repository. Letters of agreement were obtained from all collaborating clinicians.

\section{Data availability}

Study data for the primary analyses presented in this manuscript are available upon reasonable request from the corresponding and senior author.

\section{Results}

\section{Clinical}

Clinical data were collected on 6 patients from 5 families (patients 1-6) who are homozygous for the c.1387A>G FKRP mutation and 3 patients from 2 families with compound heterozygous FKRP mutations, c. $1387 \mathrm{~A}>\mathrm{G}$ and c.826C $>\mathrm{A}$ (patients 7-9). Genotypes and clinical data are summarized in table 1 . Homozygous c.1387A $>\mathrm{G}$ mutations were found in a seventh patient (patient 0 ) through clinical testing in The University of Iowa's Molecular Pathology Laboratory, but we were unable to obtain clinical information. This seventh homozygous c.1387A $>\mathrm{G}$ patient was only included in the genetic analysis.

The average current age of the homozygous patients is 9.3 years (range 4-19 years). All are of Hispanic ethnicity; some individuals reported a history of family members emigrating from central Mexico (figure 1A). Three of the 6 patients are male. All patients for whom details of early course are available had onset of symptoms (hypotonia and delayed motor milestones) before age 1 year. All patients learned to sit, but most (5 of the 6) patients never walked independently. Many started using a wheelchair by age 1-2 years. One patient walked at 2.5 years but required a wheelchair fulltime at age 8 years. Cognition is normal to mildly impaired; brain imaging (MRI or CT) and vision are normal. Most patients are currently speaking in sentences. Creatine kinase levels were $>10 \times$ normal (average 11,695 IU/L). All 3 of the patients who underwent echocardiogram had normal ejection fractions (EFs) at ages 3, 9, and 19 years.

The average current age of the 3 patients with compound heterozygous mutations in FKRP (c.1387A $>\mathrm{G}$ and c. $826 \mathrm{C}>\mathrm{A}$ ) is 19.3 years (range $7-29$ years). They met initial developmental milestones on time (sitting, walking, and talking) when details were known. They presented with hypotonia, difficulty with stairs, and muscle hypertrophy in childhood from age $<2$ years to $<10$ years. The youngest patient ( 7 years) is still ambulatory. The other 2 patients became wheelchair dependent at ages 12 and 16 years. Cognition is normal. Ejection fraction on echocardiogram was normal for the youngest patient (EF 59\% at age 7 years) but was decreased for the 2 other patients (EFs 44\% at age 22 years and $35-40 \%$ at age 21 years).

\section{Genetic analysis}

All homozygous FKRP c.1387A $>\mathrm{G}$ patients report Hispanic ethnicity. Two compound heterozygous FKRP c.1387A $>\mathrm{G}$ / c.826C $>\mathrm{A}$ patients (siblings) reported Hispanic ethnicity, with the mother carrying FKRP c.1387A $>$ G. The other patient with the FKRP c.1387A>G/c.826C >A genotype reported a father with Hispanic ethnicity. All 3 homozygous FKRP c.1387A $>\mathrm{G}$ cases in the literature also reported Hispanic ethnicity. Reported family origins of current and published cases localize to central Mexico (figure 1A). Genome-wide SNPs from 5 unrelated homozygous c.1387A $>\mathrm{G}$ patients (patients $0,3,4,5$, and 6 ) and 1 compound heterozygous c.1387A $>\mathrm{G} / \mathrm{c} .826 \mathrm{C}>\mathrm{A}$ patient (patient 9) were compared with 1000 Genomes Project populations with varying degrees of continental Native American, European, and African admixture. The genomic ancestry of FKRP c.1387A $>\mathrm{G}$ patients showed largely Native American fractions (37\%-74\%) followed by European $(22 \%-53 \%)$, consistent with cosmopoli$\tan$ Mexican ancestry (figure 1B). Patient 9, with c.1387A>G/ c.826C $>$ A genotype, had a European ancestry fraction of $72 \%$, consistent with 1 Hispanic parent. Three additional homozygous FKRP c.826C $>\mathrm{A}$ patients showed predominantly European ancestry (patients A, B, and C, figure 1B). Finescale heterozygosity analysis surrounding the FKRP locus on chromosome 19 revealed a $\sim 500$-kb region of shared homozygosity between the FKRP c.1387A>G patients, and the decay of haplotype sharing (figure 1C) indicated that c. $1387 \mathrm{~A}>\mathrm{G}$ is a founder mutation. In the 3 homozygous FKRP c.826C $>\mathrm{A}$ patients of European ancestry, a smaller $\sim 150$-kb region of shared homozygosity confirmed that c. $826 \mathrm{C}>\mathrm{A}$ is also a founder mutation. Phased haplotypes from the compound heterozygous FKRP patient (c.1387A>G) 
Table 1 Summary of clinical data

\begin{tabular}{|c|c|c|c|c|c|c|c|c|c|}
\hline Patient & 1 & $2^{a}$ & $3^{a}$ & 4 & 5 & 6 & $7^{b}$ & $8^{b}$ & 9 \\
\hline Allele $2^{c}$ & c. $1387 A>G$ & c. $1387 A>G$ & c. $1387 A>G$ & c. $1387 A>G$ & c. $1387 A>G$ & c. $1387 A>G$ & c. $826 \mathrm{C}>\mathrm{A}$ & c. $826 C>A$ & c. $826 \mathrm{C}>\mathrm{A}$ \\
\hline Age $(y) /$ sex & $4 / \mathrm{M}$ & $4 / F$ & $6 / M$ & 9/M & $14 / F$ & $19 / F$ & $7 / F$ & $22 / \mathrm{M}$ & $29 / M$ \\
\hline Ethnicity & $\mathrm{H}$ & $\mathrm{H}$ & $\mathrm{H}$ & $\mathrm{H}$ & $\mathrm{H}$ & $\mathrm{H}$ & $\mathrm{H}$ & $\mathrm{H}$ & $\mathrm{H} / \mathrm{C}$ \\
\hline Consanguinity & Y & $\mathrm{N}$ & $\mathrm{N}$ & Y & U & $\mathrm{N}$ & $\mathrm{N}$ & $\mathrm{N}$ & $\mathrm{N}$ \\
\hline Age at onset & $<2 y$ & $9 \mathrm{mo}$ & $4 \mathrm{mo}$ & Birth & $8 \mathrm{mo}$ & $<2 y$ & $<2 y$ & $<2 y$ & $2-10 y$ \\
\hline First sitting & $5 \mathrm{mo}$ & $<1 \mathrm{y}$ & Normal age & $6 y$ & $1 \mathrm{y}$ & $8 \mathrm{mo}$ & $\begin{array}{l}\text { Normal } \\
\text { age }\end{array}$ & $\begin{array}{l}\text { Normal } \\
\text { age }\end{array}$ & $<1 \mathrm{y}$ \\
\hline First walking & NA & NA & NA & NA & NA & $2.5 \mathrm{y}$ & $1 \mathrm{y}$ & $1 \mathrm{y}$ & $9 \mathrm{mo}$ \\
\hline First words & $18-21 \mathrm{mo}$ & $1 \mathrm{y}$ & Normal age & $1 \mathrm{y}$ & $\begin{array}{l}\text { Normal } \\
\text { age }\end{array}$ & $18 \mathrm{mo}$ & $\begin{array}{l}\text { Normal } \\
\text { age }\end{array}$ & $1 \mathrm{y}$ & $1 \mathrm{y}$ \\
\hline $\begin{array}{l}\text { Cognitive } \\
\text { function }\end{array}$ & $\begin{array}{l}\text { Mild } \\
\text { impairment }\end{array}$ & Normal & $\begin{array}{l}\text { Mild } \\
\text { impairment }\end{array}$ & Normal & Normal & $\begin{array}{l}\text { Mild } \\
\text { impairment }\end{array}$ & Normal & Normal & Normal \\
\hline $\begin{array}{l}\text { Age FT } \\
\text { wheelchair }\end{array}$ & NA & $1 \mathrm{y}$ & $2-3 y$ & $1 \mathrm{y}$ & NA & $8 y$ & NA & $12 \mathrm{y}$ & $16 y$ \\
\hline $\begin{array}{l}\text { Respiratory } \\
\text { support }\end{array}$ & None & None & $\begin{array}{l}\text { Nocturnal NIV } \\
\text { at } 5 y\end{array}$ & $\begin{array}{l}\text { Cough } \\
\text { assist }\end{array}$ & None & $\begin{array}{l}\text { Trach/vent at } \\
14 \mathrm{y}\end{array}$ & None & None & $\begin{array}{l}\text { NIV at } 24 \\
y\end{array}$ \\
\hline CK & $2,800^{e}$ & $\begin{array}{l}26,810 \text { (RR: } \\
20-200)\end{array}$ & $\begin{array}{l}22,170 \text { (RR: } \\
20-200)\end{array}$ & $\begin{array}{l}2,657 \text { (RR: } \\
4-87)\end{array}$ & $U$ & $\begin{array}{l}\text { 4,038 (RR: } \\
28-170)\end{array}$ & $14,451^{\mathrm{e}}$ & $U$ & $U$ \\
\hline Brain imaging & Normal CT & Normal MRI & Normal MRI & $\begin{array}{l}\text { Normal } \\
\text { MRI }\end{array}$ & $U$ & Normal MRI & $U$ & $\begin{array}{l}\text { Normal } \\
\text { MRI }\end{array}$ & $U$ \\
\hline $\mathrm{EF}^{\mathrm{d}}$ (age) & $64 \%(3 y)$ & $U$ & $u$ & $64 \%(9 y)$ & U & $61 \%(19 y)$ & $59 \%(7 \mathrm{y})$ & $\begin{array}{l}44 \%(22 \\
\text { y) }\end{array}$ & $\begin{array}{l}35-40 \% \\
(21 \mathrm{y})\end{array}$ \\
\hline Muscle bx age & NA & NA & $2 y$ & $2 y$ & $10 \mathrm{mo}$ & $4 y$ & NA & NA & $9 y$ \\
\hline \multicolumn{10}{|c|}{$\begin{array}{l}\text { Abbreviations: } B x=\text { biopsy; } C=\text { Caucasian; } C K=\text { creatine kinase; } E F=\text { ejection fraction; } F T \text { wheelchair = full-time wheelchair use; } H=\text { Hispanic; } N A=\text { not } \\
\text { applicable; NIV = noninvasive ventilation; normal age = specific age is not known but considered within a normal range; } U=\text { unknown. } \\
\text { a Patients } 2 \text { and } 3 \text { are siblings. } \\
\text { b Patients } 7 \text { and } 8 \text { are siblings. } \\
\text { c Allele } 1 \text { for all patients is c.1387A>G. } \\
\text { d EF measured by echocardiogram. } \\
\text { e CK reference range unknown. RR: CK reference range in U/L. }\end{array}$} \\
\hline
\end{tabular}

c. $826 \mathrm{C}>\mathrm{A}$ ) revealed a compound diplotype of the 2 founder mutations (figure 1D) and confirmed that these 2 founder mutations occurred on different ancestral chromosomes. The range of physical lengths of the c.1387A $>\mathrm{G}$ ancestral segments were $0.98 \mathrm{Mb}$ in patient $3,1.38 \mathrm{Mb}$ in patient $5,1.52$ $\mathrm{Mb}$ in patient $6,2.32 \mathrm{Mb}$ in patient 0 , and $4.48 \mathrm{Mb}$ in patient 4. The estimated age of the c.1387A $>\mathrm{G}$ founder mutation was 59.9 generations (95\% confidence interval 10.8-123.5), which is $\sim 1,200-1,500$ years old, assuming 20 - to 25 -year average generation spans.

\section{Muscle biopsy histopathology}

Muscle biopsies from patients with FKRP c.1387A>G mutations (4 homozygous and 1 compound heterozygous c. $1387 \mathrm{~A}>\mathrm{G} / \mathrm{c} .826 \mathrm{C}>\mathrm{A}$ ) were reviewed and compared with the muscle biopsy from a patient homozygous for the FKRP c.826C $>\mathrm{A}$ common founder mutation (patient $\mathrm{D}$; biopsy at age 25 years). The average age at muscle biopsy for homozygous FKRP c.1387A $>\mathrm{G}$ patients was 2.2 years. The compound heterozygous patient had a muscle biopsy at age 9 years.
Muscle biopsies from the patient homozygous for c.826C $>\mathrm{A}$ and the patient compound heterozygous for $c .1387 \mathrm{~A}>\mathrm{G}$ and c.826C $>\mathrm{A}$ (patient 9) showed similar mild to moderate dystrophic changes on $\mathrm{H} \& \mathrm{E}$ (figure $2, \mathrm{~A}$ and $\mathrm{B}$, respectively). These included increased fiber size variation with scattered atrophic and hypertrophic fibers, necrotic fibers undergoing myophagocytosis, and grouped regeneration. In contrast, muscle biopsies from 4 patients homozygous for c.1387A $>\mathrm{G}$ (patients 3-6) showed severe dystrophic pathology on H\&E staining including marked endomysial fibrosis and fatty replacement, large variation in fiber size with atrophic and very large hypertrophic fibers, conspicuous myonecrosis/ myophagocytosis, and grouped regeneration (figure 2, C and $\mathrm{D}$ ). Some biopsies could be classified as "end stage" because of the extensive loss of muscle fibers.

\section{Immunostaining}

IF staining was evaluated centrally in a blinded manner (K.A.J. and S.A.M.). Table 2 outlines IF staining quantification results. The 4 patients homozygous for c.1387A $>\mathrm{G}$ (patients 

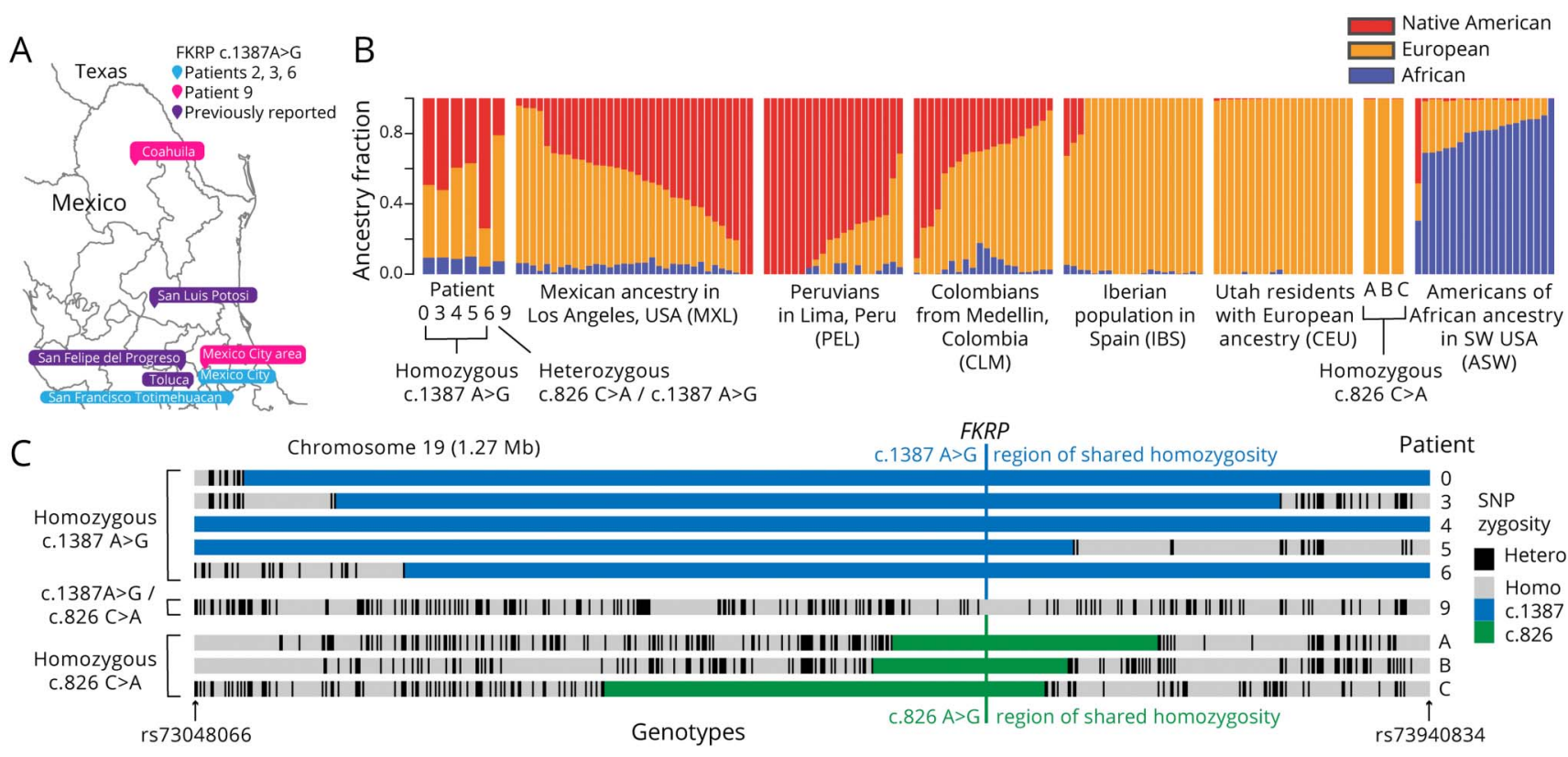

(n)

c.1387 A>G |region of shared homozygosity

$$
\text { C. } 826 \mathrm{C}>\mathrm{A}
$$

Patient
c.1387 A>G, Hap1 ||||| | | |||| ||||||| | || | | | | || || || || || || || |||
c.1387 A>G, Hap2 ||| || | ||||| ||||||| | | || | | | || | || | || || || || |||
c.1387 A>G, Hap2 ||I|| | | |||| ||||||| ||| | || || || | || || || ||||
c.826 C>A, Hap1 I||I ||||||| ||| | || ||||||||||| |||||||||| || ||| ||||||| |||

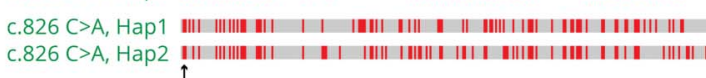
rs73048066
Phased haplotypes

FKRP

Patient

(A) Map of reported family origins of patients homozygous for FKRP c.1387A>G. Blue markers represent patients 2, 3 (siblings), and 6, pink markers represent patient 9's distant grandparents, and purple markers represent 3 previously reported homozygous FKRP c.1387A>G cases. (B) Global ancestry proportions estimated with ADMIXTURE ( $K=3$ ) for FKRP patients $0,3,4,5,6,9, A, B$, and $C$, compared with 1000 Genomes Project samples from unrelated Native Americans (MXL, 34 samples; PEL 20 samples; CLM 20 samples), Europeans (IBS, 20 samples; CEU 20 samples), and African Americans (ASW, 20 samples). Continental ancestry fraction is shown as Native American (red), European (orange), and African (blue). (C) Heterozygosity for 701 SNPs from chr19:46,664,561-47,933,257 (hg19), with shared homozygous regions for c.1387A>G highlighted in blue and c.826C $>A$ in green. (D) Phased haplotypes from patient 9 (heterozygous c. $1387 \mathrm{~A}>\mathrm{G} / \mathrm{c} .826 \mathrm{C}>\mathrm{A})$, patient $5(\mathrm{c} .1387 \mathrm{~A}>\mathrm{G})$, and patient $\mathrm{B}(\mathrm{c} .826 \mathrm{C}>\mathrm{A})$ with red/gray indicating the allele at each SNP position and the minimally shared homozygous regions highlighted in blue/green. SNP = single nucleotide polymorphism.

3-6) all showed largely decreased to absent glycosylated $\alpha$-DG positivity $(0-1+)$ with the IIH6 antibody, and mild variable decreases in $\beta$-DG, dystrophin, and merosin. The patient heterozygous for c.1387A $>\mathrm{G} / \mathrm{c} .826 \mathrm{C}>\mathrm{A}$ (patient 9) and a patient homozygous for $\mathrm{c} .826 \mathrm{C}>\mathrm{A}$ (patient $\mathrm{D}$ ) both showed a much more variable pattern of $\alpha$-DG glycosylation loss with some fibers retaining a normal staining intensity $(0-3+)$. These biopsies also showed mild variable decreases in $\beta$-DG, dystrophin, and merosin. Representative images of IF staining are shown in figure 3 with normal control (figure 3, $\mathrm{A}-\mathrm{D}$ ), homozygous c.826C $>\mathrm{A}$ (patient $\mathrm{D}$; figure 3, E-H), and 2 of the homozygous $1387 \mathrm{~A}>\mathrm{G}$ patients (patients 3 and 4; figure 3, I-L and M-P, respectively).

\section{Western blotting}

Gradient gel separation of WGA preparations derived from frozen muscle biopsies showed that each patient with FKRP mutations has reduced molecular weight $\alpha$-DG (figure 4). These same patients have lost $\alpha$-DG functional glycosylation as demonstrated by the absence or near absence of IIH6 binding. The smaller molecular weight of $\alpha$-DG in the 2 patients homozygous for FKRP c.1387A $>\mathrm{G}$ suggests that this mutation results in a greater degree of $\alpha$-DG hypoglycosylation.

\section{Discussion}

We present the clinical features, genetic analysis, and muscle pathology of 6 individuals from 5 unrelated families who are homozygous for FKRP c.1387A $>\mathrm{G}$ and 3 compound heterozygous patients from 2 unrelated families for FKRP c. $1387 \mathrm{~A}>\mathrm{G}$ and c.826C $>\mathrm{A}$. Our results expand on the phenotype of the 3 previously reported cases with this founder mutation. Five of our cases presented with a typical CMD phenotype and never walked independently, consistent with previous reports. ${ }^{6,11,12}$ The remaining patient presented before age 2 years with delayed acquisition of motor skills, and although the patient acquired independent walking, this was lost by age 8 years. None of our patients had overt abnormalities in eye or brain development, reported in some cases of FKRP-related CMD with different mutations. ${ }^{19-22}$ Based 

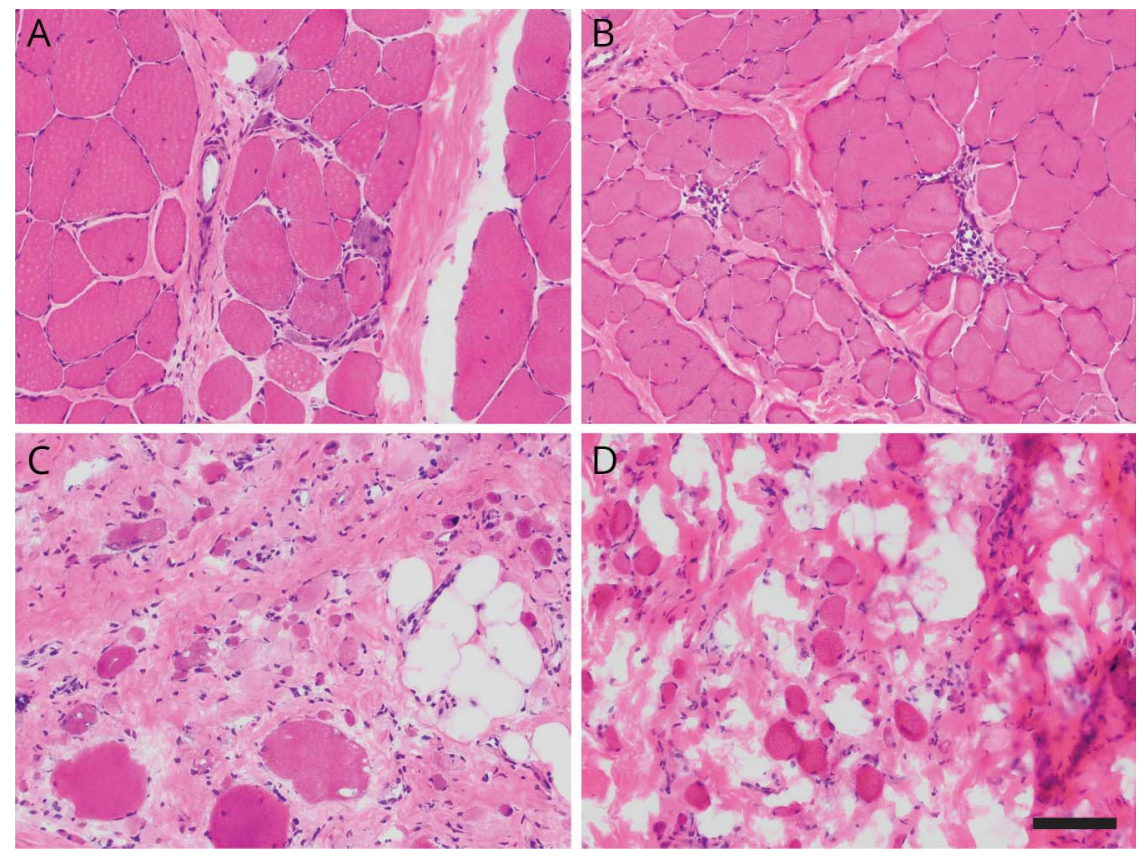

(A) Representative image of muscle biopsy from a patient homozygous for the European common mutation in FKRP C.826C $>$ A (patient $D$ ) showing mild to moderate dystrophic changes. (B) Representative image of muscle biopsy from patient 9 (heterozygous for c.1387A $>\mathrm{G}$ and c.826C>A) showing similar changes to the biopsy in part $A$. ( $C$ and $D$ ) Representative images from patients 3 and 4 (both homozygous for c.1387A>G) showing a very severe dystrophic, nearly end-stage histopathology. Scale bar $=100 \mu \mathrm{m}$, equivalent for all photomicrographs.

on all known cases to date, FKRP c.1387A $>\mathrm{G}$ mutations do not appear to be associated with the more severe muscle-eyebrain phenotype.

In contrast, the patients with compound heterozygous mutations (c.1387A $>\mathrm{G} / \mathrm{c} .826 \mathrm{C}>\mathrm{A}$ ) had a milder and more slowly progressive course; all achieved walking at the expected age of 1 year. This is consistent with what is reported in other patients who have compound heterozygous mutations with 1 c. $826 \mathrm{C}>\mathrm{A}$ allele. ${ }^{8}$

Cardiac function may be impaired in both CMD and LGMD2I because of FKRP mutations. ${ }^{23-25}$ None of the patients homozygous for FKRP c.1387A $>\mathrm{G}$ who underwent testing in our series have cardiomyopathy, but they were young at the last echocardiogram (ages 3, 9, and 19 years) and may develop abnormal cardiac function later in life. Two of the 3 compound heterozygous patients had decreased EF on echocardiogram, ages 21 and 22 years at the time of evaluation. The probability of cardiomyopathy in patients with FKRP mutations increases with age, most commonly occurring in adulthood, ${ }^{23-25}$ and therefore, patients should be appropriately screened.

Three of the 6 patients homozygous for the FKRP c.1387A $>\mathrm{G}$ mutation use some sort of respiratory support in our series, despite the young average age of the cohort, and a single patient with compound heterozygous mutations started using noninvasive ventilation at age 24 years. These observations emphasize the importance of monitoring respiratory status in these patients.

Microarray analysis confirms that the FKRP c.1387A $>$ G allele is part of a $\sim 500-\mathrm{kb}$ shared homozygous segment on

Table 2 Immunofluorescence staining quantification

\begin{tabular}{lllllll}
\hline Patient number & $\mathbf{3}$ & $\mathbf{4}$ & $\mathbf{5}$ & $\mathbf{6}$ & $\mathbf{9}$ & $\mathbf{D}^{\mathbf{a}}$ \\
\hline Genotype & $\mathrm{c} .1387 \mathrm{~A}>\mathrm{G}$ & $\mathrm{c} .1387 \mathrm{~A}>\mathrm{G}$ & $\mathrm{c} .1387 \mathrm{~A}>\mathrm{G}$ & $\mathrm{c} .1387 \mathrm{~A}>\mathrm{G}$ & $\mathrm{c} .1387 \mathrm{~A}>\mathrm{G} / \mathrm{c} .826 \mathrm{C}>\mathrm{A}$ & $\mathrm{c} .826 \mathrm{C}>\mathrm{A}$ \\
\hline $\mathbf{a - D G}$ (IIH6) & $0-1+$ & $0-1+$ & $0-1+$ & $0-1+$ & $0-3+$ & $0-3+$ \\
\hline $\boldsymbol{\beta - D G}$ & $1-3+$ & $2-3+$ & $3+$ & 2 & $2-3+$ & $3+$ \\
\hline Dystrophin & $2-3+$ & $3+$ & $2-3+$ & $3+$ & $2-3+$ & $2-3+$ \\
\hline Merosin & $1-3+$ & $2-3+$ & $3+$ & $3+$ & $3+$
\end{tabular}



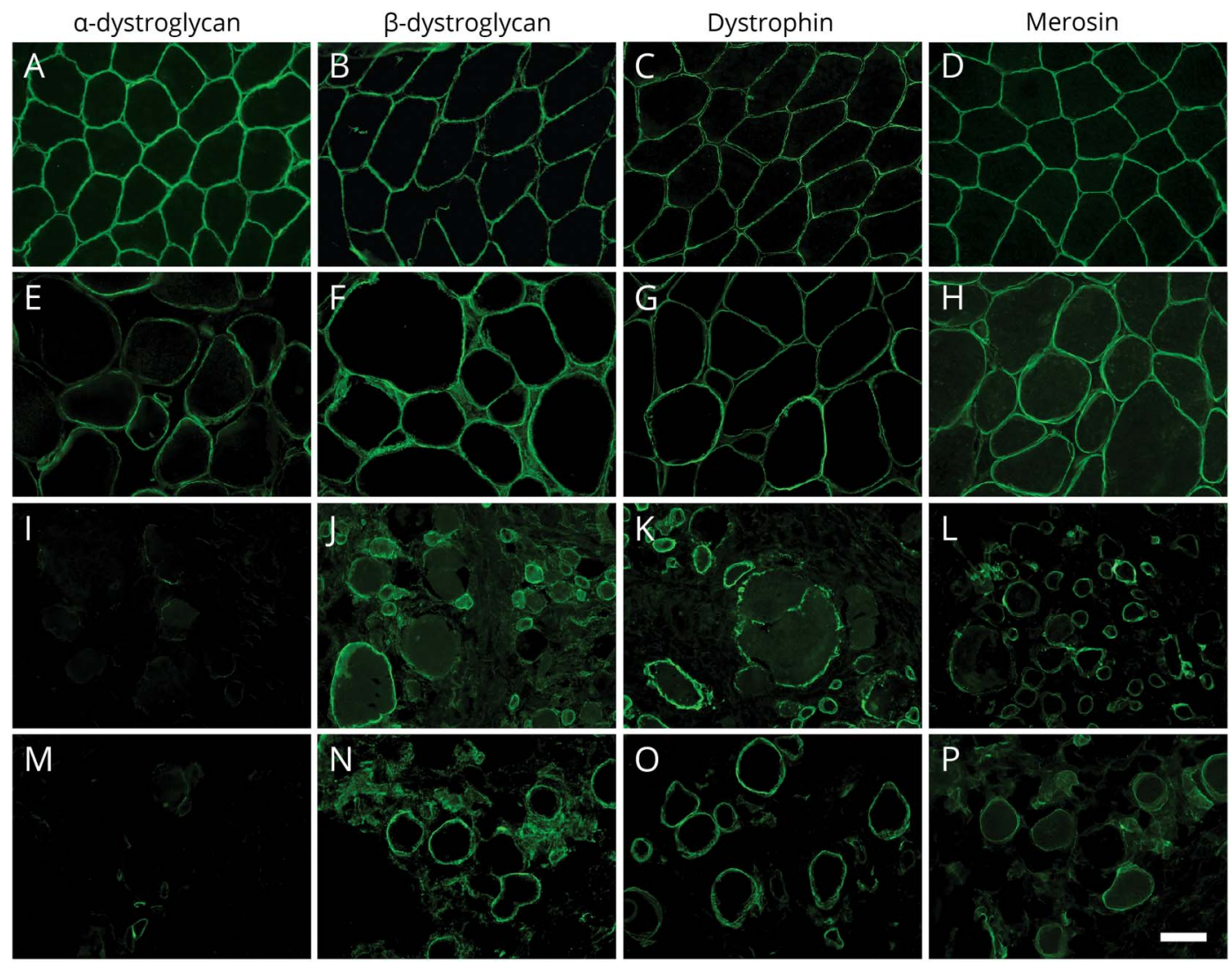

(A-D) Normal control muscle staining patterns for each of the antibodies. (E-H) Representative images from patient $D$ homozygous for the European common mutation (c.826C>A). (I-L) Representative images from patient 3 homozygous for C.1387A>G. (M-P) Representative images from patient 4 homozygous for c. $1387 \mathrm{~A}>\mathrm{G}$. Scale bar $=50 \mu \mathrm{m}$, equivalent for all photomicrographs.

chromosome 19. The size of the homozygous interval and haplotype analysis indicate that the allele originated from a common ancestor approximately 60 generations ago. Compared with the smaller $\sim 150-\mathrm{kb}$ homozygous segment associated with the c.826C $>\mathrm{A}$ allele of European origin, the c. $1387 \mathrm{~A}>\mathrm{G}$ allele has a more recent origin, but still likely predates European settlement in the Americas. Family history information for the cases reported here (and previously ${ }^{11,12}$ ) suggests an origin in central Mexico (figure 1A).

The common European founder mutation (c.826C >A, p.Leu276Ile) is found in many European populations, and the mutation is thought to have occurred once in a common ancestor. ${ }^{6,7,26,27}$ FKRP c.826C $>\mathrm{A}$ has an increased prevalence in Scandinavian countries, ${ }^{28}$ leading to the speculation that the founder mutation occurred in the Scandinavian population. Other founder mutations have also been reported as summarized in table $3 .^{29-31}$

Muscle biopsies of patients homozygous for FKRP c.1387A $>\mathrm{G}$ showed severe dystrophic histopathology, and immunostaining showed greatly decreased to absent fully glycosylated $\alpha-\mathrm{DG}$, consistent with other dystroglycanopathies manifesting a CMD phenotype. ${ }^{6}$ The muscle biopsies also showed variable, slightly reduced expression of merosin, which is comparable to findings in 2 previously reported homozygous FKRP c.1387A $>\mathrm{G}$ cases. ${ }^{11}$ By Western blotting, $\alpha-D G$ glycosylation was reduced to a greater degree in patients homozygous for FKRP c.1387A>G compared with patients with either compound heterozygous mutations c. $1387 \mathrm{~A}>\mathrm{G} / \mathrm{c} .826 \mathrm{C}>\mathrm{A}$ or homozygous FKRP c.826C $>\mathrm{A}$ mutations. It has been previously suggested that there is a relationship between the level of $\alpha$-DG glycosylation and clinical phenotype in patients with FKRP mutations ${ }^{32}$; however, this relationship could not be confirmed in other studies. ${ }^{33-35}$ Our finding of further decreased $\alpha$-DG glycosylation in those homozygous for c.1387A $>\mathrm{G}$ compared with those with milder phenotypes supports the interpretation that the degree of $\alpha$-DG hypoglycosylation is relevant for the severity of the phenotype.

The characterization of the phenotype associated with homozygous FKRP c.1387A $>\mathrm{G}$ mutations provided in this report adds to those previously described and will aid in the diagnosis and counseling regarding prognosis of patients with this rare mutation. Genetic analysis indicates that this mutation is of Mexican origin, and further genetic analysis of the specific population of origin may be of interest. In addition, 

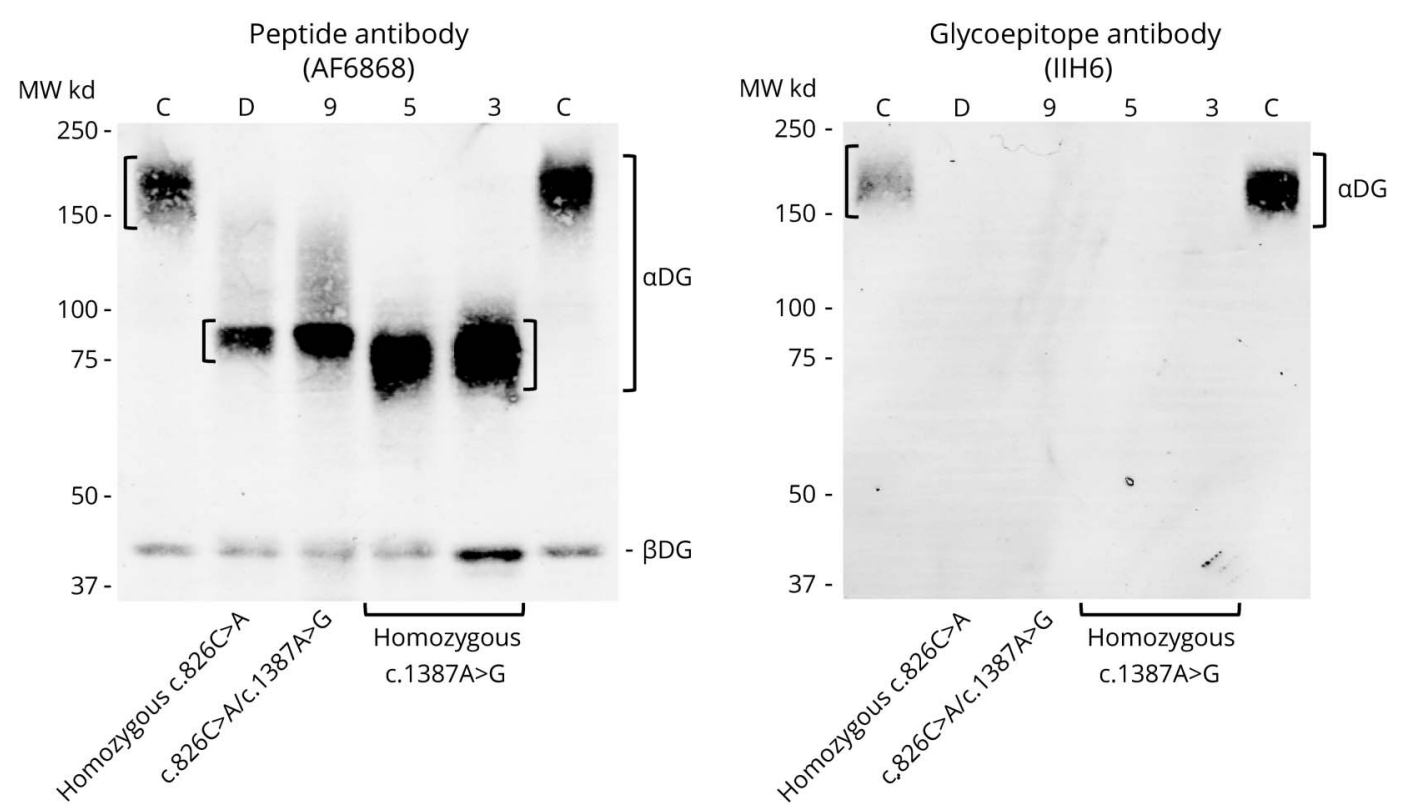

The antipeptide antibody (AF6868) shows greatly reduced molecular weight for a-DG in each of the patients with FKRP mutations. Fully glycosylated control (C) $a-D G$ is $>150 \mathrm{kd}$, whereas the $a-D G$ from homozygous c.1387A $>G$ patients ( 3 and 5) ranges from $\sim 65-90 \mathrm{kd}$, and the $a-D G$ from homozygous c.826C $>A$ (D) or compound heterozygous c.1387A $>\mathrm{G} / \mathrm{c} .826 \mathrm{C}>\mathrm{A}$ (9) patients ranges from $\sim 75-90 \mathrm{kd}$. The smaller molecular weight a-DG observed in homozygous c.1387A $>\mathrm{G}$ patients suggests a greater degree of hypoglycosylation than that of c.826C $>$ A patients. Each patient with FKRP mutations has lost functional glycosylation and no longer binds the anti-glycoepitope antibody (IIH6). The AF6868 antibody binds to epitopes on both $\alpha$-DG and $\beta$-DG. The $\beta$-DG bands show the relative amounts of protein loaded in each lane. Lanes were loaded equivalently in both gels. These images are representative of blots performed 3 or 4 times for each patient sample.

our findings are consistent with the idea that the more severe clinical phenotype associated the c.1387A $>\mathrm{G}$ mutation is explained, in part, by the greater reduction of $\alpha$-DG glycosylation relative to other genotypes examined; however, clarity on this issue requires additional study.

\section{Author contributions}

A.J. Lee and K.A. Jones: study concept/design, analysis/ interpretation of data, and drafting/revision of the manuscript. R.J. Butterfield: study design, acquisition/analysis/ interpretation of data, and revision of the manuscript. M.O. Cox: analysis/interpretation of data and revision of the manuscript. C.G. Konersman, C. Grosmann, J.E. Abdenur, M.
Boyer, B. Beson, C. Wang, J.J. Dowling, M.A. Gibbons, and A. Ballard: acquisition of data and revision of the manuscript. J.S. Janas, R.T. Leshner, S. Donkervoort, C.G. Bönnemann, and D.M. Malicki: acquisition of data and revision of the manuscript. R.B. Weiss: study design, analysis/interpretation of data, and drafting/revision of the manuscript. S.A. Moore: study concept/design, analysis/interpretation of data, and revision of the manuscript. K.D. Mathews: study concept/design, analysis/interpretation of data, and revision of the manuscript.

\section{Acknowledgment}

The authors acknowledge The University of Iowa histotechnologist Terese Nelson for performing the

Table 3 Founder mutations in FKRP

\begin{tabular}{|c|c|c|c|c|}
\hline Mutation & Protein change & Population & Phenotype & Author (year) \\
\hline c. $826 C>A$ & p.Leu276Ile & European ${ }^{a}$ & LGMD2I & Frosk et al. $(2005)^{26}$ \\
\hline c. $1364 C>A$ & p.Ala455Asp & Tunisian & CMD with brain involvement & Louhichi et al. (2004) \\
\hline$c .545 A>G$ & p.Tyr182Cys & Chinese & Asymptomatic & Fu et al. $(2016)^{31}$ \\
\hline C. $1100 \mathrm{C}>\mathrm{T}$ & p.lle367Thr & South African Afrikaner & LGMD2I & Mudau et al. $(2016)^{29}$ \\
\hline c. $1387 A>G$ & p.Asn463Asp & Mexican & CMD without brain involvement & \\
\hline
\end{tabular}

Abbreviations: CMD = congenital muscular dystrophy; LGMD2I = limb-girdle muscular dystrophy type 21 .

Reported founder mutations in FKRP. Phenotypes described are for patients homozygous for these mutations.

${ }^{a}$ Genetic analysis was performed in the Hutterites, and a shared region was also identified in samples of other European populations. Further research showed the highest prevalence of FKRP C.826C $>A$ in Scandinavian populations. ${ }^{28}$ 
histology and immunofluorescence staining. Initial sequencing and analysis for patient 4 was provided by the Broad Institute of MIT and Harvard Center for Mendelian Genomics (Broad CMG) and was funded by the National Human Genome Research Institute, the National Eye Institute, and the National Heart, Lung and Blood Institute grant UM1 HG008900 to Daniel MacArthur and Heidi Rehm.

\section{Study funding}

This research was funded by a Paul D. Wellstone Muscular Dystrophy Cooperative Research Center grant (NIH U54 NS053672). M.B. is partially supported by a grant from the Fry Family Foundation (16084001).

\section{Disclosure}

A.J. Lee received funding from the Iowa Wellstone Muscular Dystrophy Cooperative Research Center, U54, NS053672. K.A. Jones reports no disclosures. R.J. Butterfield is supported by NIH grant 1K08NS097631-01. He is receiving funding via contracts for clinical trials from PTC Therapeutics, Sarepta Therapeutics, Pfizer, Marathon, Biogen, Summit Therapeutics, Santhera Pharmaceuticals, and aTyr Pharmaceuticals. He serves on the scientific advisory boards of Sarepta Therapeutics, Biogen, PTC Therapeutics, and Wave Life Sciences. M.O. Cox received funding from the Iowa Wellstone Muscular Dystrophy Cooperative Research Center, U54, NS053672. C.G. Konersman previously served as a consultant of Sarepta Therapeutics for their medication, ExonDys51. C. Grosmann sits on an advisory board of Sarepta Therapeutics and receives funding from Sarepta and Italfarmaco through clinical trial contracts. J.E. Abdenur and M. Boyer report no disclosures. B. Beson receives MDA grant money for his neuromuscular clinic. C. Wang reports no disclosures. J.J. Dowling is a scientific advisory board member of the RYR1 Foundation, the Muscular Dystrophy Association, and Dynacure. He does occasional biomedical consulting for GLG and Guidepoint consulting. M.A. Gibbons, A. Ballard, J.S. Janas, R.T. Leshner, S. Donkervoort, C.G. Bönnemann, and D.M. Malicki report no disclosures. R.B. Weiss is supported by NIH grant NS085238. S.A Moore has fee for service contracts with Sarepta Therapeutics, Inc. and Flagship Biosciences. He received funding from the Iowa Wellstone Muscular Dystrophy Cooperative Research Center, U54, NS053672. K.D. Mathews received funding from the Iowa Wellstone Muscular Dystrophy Cooperative Research Center, U54, NS053672. She also receives research funding from the CDC (U01 DD000189) and clinical trial support related to DMD from Sarepta, Pfizer, Santhera, Roche, FibroGen, and Italfarmaco. She has served on the advisory boards of Sarepta and Santhera. Full disclosure form information provided by the authors is available with the full text of this article at Neurology.org/NG.

\section{Publication history}

Received by Neurology: Genetics October 17, 2018. Accepted in final form January 2, 2019.

\section{References}

1. Ibraghimov-Beskrovnaya O, Ervasti JM, Leveille CJ, Slaughter CA, Sernett SW, Campbell KP. Primary structure of dystrophin-associated glycoproteins linking dystrophin to the extracellular matrix. Nature 1992;355:696-702.

2. Ervasti JM, Campbell KP. A role for the dystrophin-glycoprotein complex as a transmembrane linker between laminin and actin. J Cell Biol 1993;122:809-823.

3. Henry MD, Campbell KP. Dystroglycan inside and out. Curr Opin Cell Biol 1999;11: 602-607.

4. Cohn RD. Dystroglycan: important player in skeletal muscle and beyond. Neuromuscul Disord 2005;15:207-217.

5. Kanagawa M, Kobayashi K, Tajiri M, et al. Identification of a post-translational modification with ribitol-phosphate and its defect in muscular dystrophy. Cell Rep 2016;14:2209-2223.

6. Brockington $\mathrm{M}$, Blake DJ, Prandini $\mathrm{P}$, et al. Mutations in the fukutin-related protein gene (FKRP) cause a form of congenital muscular dystrophy with secondary laminin alpha2 deficiency and abnormal glycosylation of alpha-dystroglycan. Am J Hum Genet 2001;69:1198-1209.

7. Brockington M, Yuva Y, Prandini P, et al. Mutations in the fukutin-related protein gene (FKRP) identify limb girdle muscular dystrophy 2I as a milder allelic variant of congenital muscular dystrophy MDC1C. Hum Mol Genet 2001; $10: 2851-2859$.

8. Stensland E, Lindal S, Jonsrud C, et al. Prevalence, mutation spectrum and phenotypic variability in Norwegian patients with Limb Girdle Muscular Dystrophy 2I. Neuromuscul Disord 2011;21:41-46.

9. Kang PB, Feener CA, Estrella E, et al. LGMD2I in a North American population. BMC Musculoskelet Disord 2007;8:115.

10. Yamamoto LU, Velloso FJ, Lima BL, et al. Muscle protein alterations in LGMD2I patients with different mutations in the Fukutin-related protein gene. J Histochem Cytochem 2008;56:995-1001.

11. MacLeod H, Pytel P, Wollmann R, et al. A novel FKRP mutation in congenital muscular dystrophy disrupts the dystrophin glycoprotein complex. Neuromuscul Disord 2007; 17:285-289.

12. Navarro-Cobos MJ, Gonzalez-Del Angel A, Estandia-Ortega B, et al. Molecular analysis confirms that FKRP-related Disorders are underdiagnosed in Mexican patients with neuromuscular diseases. Neuropediatrics 2017;48:442-450.

13. Chang CC, Chow CC, Tellier LC, Vattikuti S, Purcell SM, Lee JJ. Second-generation PLINK: rising to the challenge of larger and richer datasets. Gigascience 2015;4:7.

14. Das S, Forer L, Schönherr S, et al. Next-generation genotype imputation service and methods. Nat Genet 2016;48:1284-1287.

15. Gandolfo LC, Bahlo M, Speed TP. Dating rare mutations from small samples with dense marker data. Genetics 2014;197:1315-1327.

16. Alexander DH, Novembre J, Lange K. Fast model-based estimation of ancestry in unrelated individuals. Genome Res 2009;19:1655-1664.

17. Michele DE, Barresi R, Kanagawa M, et al. Post-translational disruption of dystroglycan-ligand interactions in congenital muscular dystrophies. Nature 2002; 418:417-422.

18. Willer T, Lee H, Lommel M, et al. ISPD loss-of-function mutations disrupt dystroglycan O-mannosylation and cause Walker-Warburg syndrome. Nat Genet 2012;44: $575-580$.

19. Quijano-Roy S, Marti-Carrera I, Makri S, et al. Brain MRI abnormalities in muscular dystrophy due to FKRP mutations. Brain Dev 2006;28:232-242.

20. Beltran-Valero de Bernabe D, Voit T, Longman C, et al. Mutations in the FKRP gene can cause muscle-eye-brain disease and Walker-Warburg syndrome. J Med Genet 2004;41:e61.

21. Mercuri E, Topaloglu H, Brockington M, et al. Spectrum of brain changes in patients with congenital muscular dystrophy and FKRP gene mutations. Arch Neurol 2006;63: 251-257.

22. Van Reeuwijk J, Olderode-Berends MJ, Van den Elzen C, et al. A homozygous FKRP start codon mutation is associated with Walker-Warburg syndrome, the severe end of the clinical spectrum. Clin Genet 2010;78:275-281.

23. Kefi M, Amouri R, Chabrak S, Mechmeche R, Hentati F. Variable cardiac involvement in Tunisian siblings harboring FKRP gene mutations. Neuropediatrics 2008;39: 113-115.

24. Margeta M, Connolly AM, Winder TL, Pestronk A, Moore SA. Cardiac pathology exceeds skeletal muscle pathology in two cases of limb-girdle muscular dystrophy type 2I. Muscle Nerve 2009;40:883-889.

25. Poppe M, Bourke J, Eagle M, et al. Cardiac and respiratory failure in limb-girdle muscular dystrophy 2I. Ann Neurol 2004;56:738-741.

26. Frosk P, Greenberg CR, Tennese AA, et al. The most common mutation in FKRP causing limb girdle muscular dystrophy type 2I (LGMD2I) may have occurred only once and is present in Hutterites and other populations. Hum Mutat 2005;25:38-44.

27. Walter MC, Petersen JA, Stucka R, et al. FKRP $(826 \mathrm{C}>\mathrm{A})$ frequently causes limbgirdle muscular dystrophy in German patients. J Med Genet 2004;41:e50.

28. Sveen ML, Schwartz M, Vissing J. High prevalence and phenotype-genotype correlations of limb girdle muscular dystrophy type 2I in Denmark. Ann Neurol 2006;59: 808-815.

29. Mudau MM, Essop F, Krause A. A novel FKRP-related muscular dystrophy founder mutation in South African Afrikaner patients with a phenotype suggestive of a dystrophinopathy. S Afr Med J 2016;107:80-82.

30. Louhichi N, Triki C, Quijano-Roy S, et al. New FKRP mutations causing congenital muscular dystrophy associated with mental retardation and central nervous system abnormalities. Identification of a founder mutation in Tunisian families. Neurogenetics 2004;5:27-34. 
31. Fu X, Yang H, Wei C, et al. FKRP mutations, including a founder mutation, cause phenotype variability in Chinese patients with dystroglycanopathies. J Hum Genet 2016;61:1013-1020.

32. Brown SC, Torelli S, Brockington $\mathrm{M}$, et al. Abnormalities in alpha-dystroglycan expression in MDC1C and LGMD2I muscular dystrophies. Am J Pathol 2004;164: 727-737.

33. Alhamidi M, Brox V, Stensland E, Liset M, Lindal S, Nilssen O. Limb girdle muscular dystrophy type 2I: No correlation between clinical severity, histopathology and glycosylated alpha-dystroglycan levels in patients homozygous for common FKRP mutation. Neuromuscul Disord 2017;27: 619-626.

34. Boito CA, Fanin M, Gavassini BF, Cenacchi G, Angelini C, Pegoraro E. Biochemical and ultrastructural evidence of endoplasmic reticulum stress in LGMD2I. Virchows Arch 2007;451:1047-1055.

35. Jimenez-Mallebrera C, Torelli S, Feng L, et al. A comparative study of alphadystroglycan glycosylation in dystroglycanopathies suggests that the hypoglycosylation of alpha-dystroglycan does not consistently correlate with clinical severity. Brain Pathol 2009;19:596-611. 


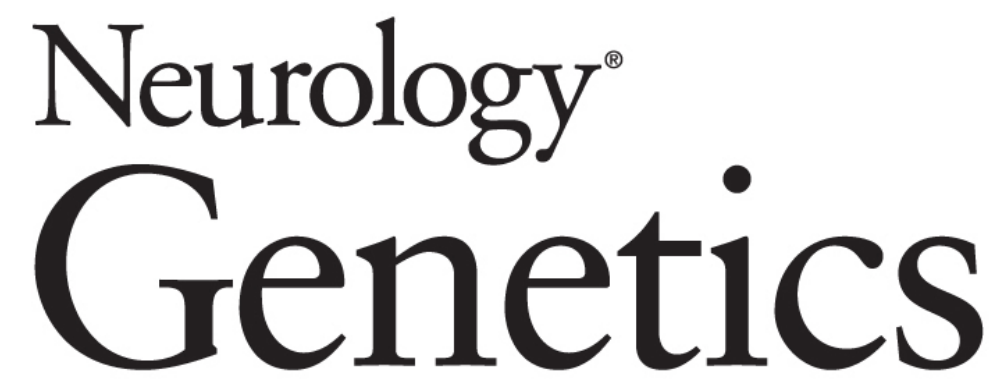

Clinical, genetic, and pathologic characterization of FKRP Mexican founder mutation c.1387A $>$ G

Angela J. Lee, Karra A. Jones, Russell J. Butterfield, et al. Neurol Genet 2019;5;

DOI 10.1212/NXG.0000000000000315

This information is current as of March 1, 2019

Neurol Genet is an official journal of the American Academy of Neurology. Published since April 2015, it is an open-access, online-only, continuous publication journal. Copyright Copyright $\odot 2019$ The Author(s). Published by Wolters Kluwer Health, Inc. on behalf of the American Academy of Neurology.. All rights reserved. Online ISSN: 2376-7839.

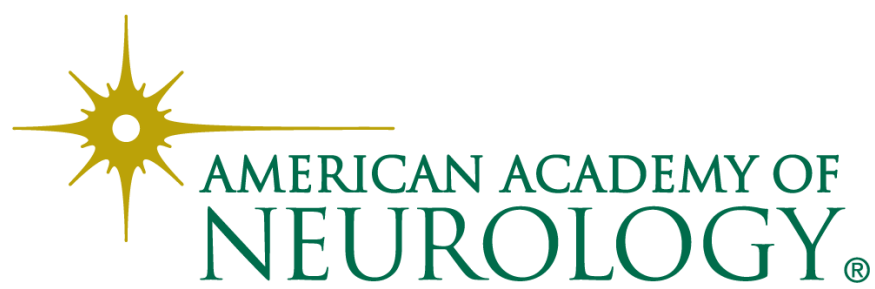




\section{Updated Information \& Services}

References

Citations

Subspecialty Collections

Permissions \& Licensing

Reprints including high resolution figures, can be found at: http://ng.neurology.org/content/5/2/e315.full.html

This article cites 35 articles, 5 of which you can access for free at: http://ng.neurology.org/content/5/2/e315.full.html\#\#ref-list-1

This article has been cited by 2 HighWire-hosted articles: http://ng.neurology.org/content/5/2/e315.full.html\#\#otherarticles

This article, along with others on similar topics, appears in the following collection(s):

All Genetics

http://ng.neurology.org//cgi/collection/all_genetics All Pediatric

http://ng.neurology.org//cgi/collection/all_pediatric

Muscle disease

http://ng.neurology.org//cgi/collection/muscle_disease

Information about reproducing this article in parts (figures,tables) or in its entirety can be found online at:

http://ng.neurology.org/misc/about.xhtml\#permissions

Information about ordering reprints can be found online:

http://ng.neurology.org/misc/addir.xhtml\#reprintsus

Neurol Genet is an official journal of the American Academy of Neurology. Published since April 2015, it is an open-access, online-only, continuous publication journal. Copyright Copyright $\odot 2019$ The Author(s). Published by Wolters Kluwer Health, Inc. on behalf of the American Academy of Neurology.. All rights reserved. Online ISSN: 2376-7839.

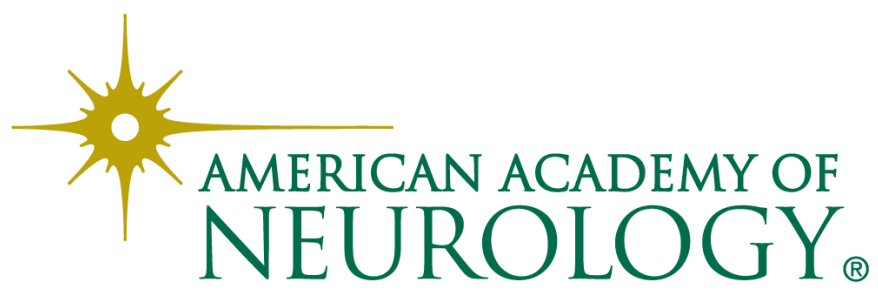

